\section{Prevalência de infecção genital pelo HPV em populações urbana e rural da Amazônia Oriental Brasileira}

\author{
Prevalence of genital HPV infection in urban and \\ rural women in the Eastern Brazilian Amazon
}

\begin{abstract}
This study investigated the prevalence and risk factors for genital infection with HPV in women from rural and urban areas in two different regions of the Eastern Brazilian Amazon. A crosssectional survey was performed in Pap screening programs, with a total sample of 444 women (233 urban and 211 rural). Uterine cervical swabs were collected for the detection of HPV DNA with the established PCR assay using MY09-MY11. All volunteers answered an epidemiological questionnaire. Bivariate and multivariate logistic regression analyses were performed to identify risk factors associated with HPV infection. Overall prevalence of HPV infection was $14.6 \%$ (15\% in urban women and $14.2 \%$ in rural). The only factor associated with HPV was marital status in the 13-25-year-old rural population, with higher HPV prevalence among single and divorced women and widows. The findings indicate the need for risk factor control strategies targeted specifically to women in rural and urban areas.
\end{abstract}

Papillomavirus Infections; Cervix Uteri; Women
Denise da Silva Pinto 1,2

Hellen Thais Fuzii 1

Juarez Antônio Simões Quaresma 1,3
No Brasil, estima-se que o câncer do colo uterino seja o terceiro mais comum na população feminina, sendo superado pelo câncer de pele não melanoma e pelo câncer de mama. Representa a segunda causa de óbito por câncer entre mulheres, com uma taxa de mortalidade de aproximadamente 4,61 por 100 mil mulheres, no ano de 2002, sendo o pico de incidência por idade entre 40 e 60 anos. As estimativas do Instituto Nacional de Câncer (INCA) apontam 18.430 novos casos de câncer do colo do útero no Brasil para o ano de 2010, sendo 1.820 novos casos somente na Região Norte. No Estado do Pará, localizado na Região Norte do país, que representa uma das áreas mais acometidas, deverão surgir, no mesmo ano, 790 novos casos da doença, sendo 330 somente na capital, Belém ${ }^{1,2}$.

Diversos fatores já foram apontados na literatura como predisponentes ao desenvolvimento de lesões do colo do útero. Aspectos sociodemográficos, comportamentais, sexuais, contraceptivos, reprodutivos e/ou clínicos tornam a mulher mais susceptível a outros fatores mais diretamente envolvidos na carcinogênese cervical, tais como inflamação local e infecção por HPV. O último é apontado pela literatura como condição necessária ao desenvolvimento de lesão intraepitelial de alto grau e câncer invasivo do colo do útero, pois o DNA viral do HPV está presente em 
mais de 90\% das lesões pré-neoplásicas e neoplásicas cervicais $3,4,5,6$.

O Estado do Pará, localizado na porção oriental da Amazônia brasileira, apresenta uma das maiores prevalências de câncer cervical no Brasil. Sua população apresenta peculiaridades sociais e comportamentais distintas entre agregados urbanos e rurais. Este estudo objetivou investigar os diferentes fatores de risco envolvidos no desenvolvimento do câncer cervical tais como fatores sociodemográficos, comportamentais e clínicos peculiares de população urbana e rural, juntamente com a detecção molecular do HPV, a fim de fornecer subsídios específicos para programas regionalizados de prevenção e manejo desta morbidade.

\section{Metodologia}

Trata-se de um estudo analítico do tipo transversal, realizado em duas regiões distintas da Amazônia Oriental Brasileira, sendo uma considerada urbana e a outra considerada rural.

A amostra urbana foi composta por mulheres atendidas na Unidade Materno-Infantil do Centro de Ciências Biológicas e da Saúde da Universidade do Estado do Pará, localizada no Município de Belém. A unidade é uma das referências para prevenção de câncer uterino, atendendo à demanda dos diversos bairros de Belém e região metropolitana.

O tamanho da amostra foi calculado tendo em conta um grau de $95 \%$ de confiança e uma taxa de erro absoluto de $5 \%$ para uma população infinita. No cálculo foi utilizada uma prevalência geral estimada da infecção genital por qualquer tipo de HPV de $25 \%$ em mulheres brasileiras de 18 a 60 anos residentes em meio urbano, de acordo com os estudos de Franco et al. 7. Dessa forma, para esta população, estimou-se o recrutamento inicial de 289 mulheres, mas permaneceram no estudo 233 amostras com material cervical viável para os testes moleculares de pesquisa do HPV, coletadas no período de janeiro a junho de 2008.

A amostra rural foi composta por mulheres residentes no Município de Tucuruí, situado a $426 \mathrm{~km}$ a sudeste de Belém. Foram incluídas no estudo mulheres cadastradas no Programa Saúde da Família da região do lago da Usina Hidrelétrica de Tucuruí - Pará (UHE), sendo esta população composta por mulheres residentes nas margens esquerda e direita do lago da UHE, incluindo as ilhas e a porção continental. De acordo com os dados obtidos no Sistema de Informação da Atenção Básica (SIAB; http://tabnet.datasus.gov. br/cgi/tabcgi.exe?siab/cnv/SIABFpa, acessado em 30/Mar/2009), a população feminina de 15 a 79 anos cadastrada na área de abrangência no início do estudo era de aproximadamente 1.119 mulheres.

O tamanho da amostra para esta população foi calculado com um grau de 95\% de confiança e uma taxa de erro absoluto de $5 \%$ para uma população finita de 1.119 habitantes do sexo feminino. No cálculo foi utilizada uma prevalência geral estimada da infecção genital por qualquer tipo de HPV de 26,6\% em mulheres brasileiras de 15 a 63 anos residentes em zona rural, de acordo com os estudos de Soares et al. ${ }^{8}$. Assim, para esta população, foi estimado um recrutamento inicial de 235 mulheres, permanecendo 211 amostras com material cervical viável para os testes moleculares de pesquisa do HPV, coletadas no período de março de 2009 a março de 2010.

As participantes que compuseram as amostra urbana e rural do estudo foram selecionadas entre mulheres sexualmente ativas que compareceram para rastreamento de rotina do câncer cervical em serviços de atenção básica de saúde das regiões envolvidas no estudo no período de janeiro 2008 a março de 2010, sendo incluídas mulheres que aceitaram voluntariamente realizar o teste de rastreamento molecular do HPV e responder ao formulário do estudo, com idade entre 13 e 75 anos, com útero e/ou colo presente e funções cognitivas preservadas no momento da coleta de dados.

O instrumento utilizado consistiu em um formulário clínico e epidemiológico padrão, aplicado antes da realização da consulta ginecológica, dividido nas seguintes partes: informações sociodemográficas e comportamentais; história sexual; história anticoncepcional; história reprodutiva; história ginecológica e dados laboratoriais (resultados dos exames). A coleta dos dados se deu por entrevistadores previamente treinados a fim de se evitar o viés de informação.

Os procedimentos da colpocitologia foram realizados com a mulher em posição ginecológica. Introduziu-se em sua vagina o espéculo de Collins para a visualização do colo do útero e do conteúdo vaginal. Nesse momento foram coletadas as amostras cervicais para a colpocitologia e biologia molecular. Os resultados da citologia foram classificados de acordo com o Sistema de Bethesda (2001) adotado pela Nomenclatura Brasileira para Laudos Citopatológicos Cervicais 9,10.

Para a obtenção de DNA das células cervicais, após a realização do esfregaço celular em lâmina, a escova cervical estéril (citobrush) contendo o material coletado foi mergulhada em um tubo de $15 \mathrm{~mL}$ com PBS (solução salina tamponada com fosfato), no qual foi lavada em PBS para que as células ficassem em suspensão. Em seguida, o tubo foi centrifugado a $2.000 \mathrm{rpm}$ para a precipi- 
tação das células cervicais, sendo então lavadas três vezes em PBS. Na última lavagem, ficaram $200 \mu \mathrm{L}$ de PBS sobre o pellet de células e, em seguida, a amostra foi congelada em freezer $-20^{\circ} \mathrm{C}$. A extração do DNA foi realizada utilizando o kit GFX (GE Healthcare).

Em seguida, para a pesquisa do DNA do HPV, foi empregado o método de reação em cadeia da polimerase (PCR), sendo utilizado para controle da extração um par de oligonucleotídeos iniciadores (primers) $R$ e $F$, que amplificaram o gene da globina, com a presença da globina atestando a qualidade da amostra cervical coletada, ou seja, existia DNA adequado para a PCR.

Ao longo do procedimento de PCR, para cada $1 \mu \mathrm{L}$ de amostra testada, a cada reação foram utilizados 100ng de DNA em 20 $\mu$ L de tampão 10x buffer composto por 20mM de Tris- $\mathrm{HCl}$ ( $\mathrm{pH} 8,4$ ou 8,6), 0,25-1,5mM de $\mathrm{MgCl}_{2}$, 50mM de $\mathrm{KCl}$; além disso foram acrescentados à reação $0,02 \mathrm{mM}$ de DNTP, 200nM de primers universais MY9 e MY11 para detecção geral de HPV e 0,25 unidades de Taq DNA polimerase. Os primers universais MY9 e MY11 são capazes de detectar os diferentes tipos de HPV em razão de seu anelamento em uma área bem delimitada e conservada do genoma viral (L1). A seguir, no aparelho termociclador, estas reações consistiram em um ciclo de desnaturação inicial de $94^{\circ} \mathrm{C}$ por 5 minutos e de 35 ciclos de amplificação de PCR. Cada ciclo consistiu em $94^{\circ} \mathrm{C}$ por 30 segundos, $52^{\circ} \mathrm{C}$ por 30 segundos e $72^{\circ} \mathrm{C}$ por 30 segundos. A extensão final do DNA amplificado ocorreu a $72^{\circ} \mathrm{C}$ por $5 \mathrm{minu}$ tos. Em seguida, as amostras foram submetidas à eletroforese em gel de agarose a $1 \%$ em TBE $1 x$. As amostras foram consideradas positivas quando o produto da PCR em gel de agarose apresentou uma banda de 440 pares de base à visualização fotográfica no Genlianse da PerkinElmer (Waltham, Estados Unidos) pelo programa GeneSnap (Syngene; http://www.syngene.com/genesnap). Tais procedimentos foram realizados de acordo com o protocolo descrito por Bernard et al. ${ }^{11}$.

O programa Excel 2007 (Microsoft Corp., Estados Unidos) foi adotado para entrada dos dados, bem como para a confecção das tabelas e gráficos, e a análise estatística foi realizada por meio dos programas Epi Info 3.5.1 (Centers for Disease Control and Prevention, Atlanta, Estados Unidos) e BioEstat 5.0 (Sociedade Civil Mamirauá, Manaus, Brasil). Na análise univariada, obteve-se para todo o grupo e separadamente nas duas populações estudadas, a prevalência da infecção pelo HPV, bem como a distribuição de frequências, medidas de dispersão e de tendência central das variáveis independentes.

Para uma investigação mais detalhada dos fatores de risco possivelmente associados à infec- ção por HPV para todo o grupo e separadamente nas duas populações estudadas, procedeu-se a uma estratificação dos dados por três faixas etárias (13 a 25 anos, 26 a 44 anos e 45 ou mais anos), sendo então empregado, na análise bivariada, o cálculo das razões de prevalências (RP) com a significância estatística verificada pelo teste do qui-quadrado $\left(\chi^{2}\right)$ e/ou exato de Fisher, considerando-se nível alfa de $5 \%$. As variáveis independentes com valor de $\mathrm{p}<0,2$ na análise bivariada estratificada por faixa etária foram incluídas em um modelo de regressão logística múltipla não condicional, sendo realizado apenas o ajuste da variável "número de parceiros sexuais durante a vida" pela variável "uso de preservativos" no modelo final em todas as faixas etárias.

O presente estudo esteve inserido no projeto Infecção pelo HPV e Câncer Cervical: Correlação Clínico-Epidemiológica e Fatores de Risco em Populações Distintas da Amazônia Brasileira, da Universidade Federal do Pará (UFPA) e contou com o apoio financeiro do Ministério da Saúde e da Organização das Nações Unidas para a Educação, Ciência e Cultura (UNESCO), estando aprovado pelo Comitê de Ética em Pesquisa para Seres Humanos do Núcleo de Medicina Tropical da Universidade Federal do Pará (parecer no . 171/2005-CEP/NMT).

\section{Resultados}

Das 444 mulheres recrutadas, 233 mulheres (52,5\%) constituíram a amostra urbana e 211 $(47,5 \%)$ compuseram a amostra rural, sendo a somatória das duas a população denominada geral. A média e a mediana de idade das mulheres de área urbana foram de 36,9 \pm 11,4 anos e 34 anos, respectivamente, ao passo que as mulheres da área rural tinham média e mediana de idade de $34,1 \pm 12,5$ anos e 33 anos, respectivamente.

Entre 444 mulheres estudadas, 14,6\% (IC95\%: $11,4 \%-17,9 \%)$ apresentavam infecção genital pelo HPV, e a prevalência dessa infecção variou entre $15 \%$ (IC95\%: 10,7\%-20,3\%) para a amostra urbana e $14,2 \%$ (IC95\%: 9,8\%-19,7\%) na amostra rural, não ocorrendo diferença significativa entre os locais de recrutamento, mesmo considerando a estratificação por faixas de idade.

Em relação à citologia cervical, 2,9\% das 444 amostras coletadas nas referidas populações da Amazônia Oriental foram consideradas insatisfatórias para o exame, ficando, portanto, sem o resultado citológico. No geral, entre as $431 \mathrm{mu}-$ lheres com amostras satisfatórias para o exame, $97,2 \%$ tiveram um resultado normal ou inflamatório na citologia e 2,8\% com alterações. Dentre estas, $0,9 \%, 0,2 \%, 0,9 \%$ e $0,5 \%$ tiveram ASCUS, 
ASGUS, LSIL e HSIL, respectivamente, e 0,5\% das mulheres apresentou carcinoma de células escamosas.

Em toda a amostra estudada, o DNA do HPV foi detectado em 33,3\% das mulheres com ASCUS; $100 \%$ das mulheres com ASGUS; $50 \%$ das mulheres com LSIL, $50 \%$ das mulheres com carcinoma de células escamosas e em $23,1 \%$ das mulheres sem resultado laboratorial de citologia cervical. Entretanto, não foi detectado DNA do HPV nas mulheres com HSIL em nenhuma das populações estudadas.

Analisando as prevalências de infecção por HPV, tendo como base o resultado da citologia cervical, verificou-se que as amostras que apresentaram anormalidades citológicas possuíam maiores prevalências de infecção genital pelo HPV. Contudo, tal resultado se mostrou estatisticamente significante somente na faixa etária de 26 a 44 anos, tendo em conta ambas as amostras do estudo (RP = 4,0; IC95\%: 1,67-9,57).

Em mulheres com citologia normal ou inflamatória, para todas as faixas de idade, a maior prevalência de HPV ocorreu na amostra urbana, sendo assim distribuídas: $17,5 \%$ nas de 13 a 25 anos; $12,9 \%$ nas de 26 a 44 anos; e 14,5\% nas de 45 ou mais anos, porém não houve diferença estatística na comparação entre as amostras urbana e rural para essa variável.

Os principais fatores associados à infecção genital por HPV entre as mulheres na faixa etária de 13 a 25 anos considerando ambas as populações na análise bivariada foram número de parceiros sexuais na vida e novos no último ano, assim como o uso de preservativos e situação conjugal. Todavia, observou-se associação significante somente em relação à situação conjugal das mulheres jovens da zona rural, uma vez que mulheres solteiras, separadas ou viúvas tiveram uma prevalência 4,3 ( $\mathrm{p}=0,0097$ ) maior de infecção pelo HPV do que mulheres que moravam com um companheiro ou eram casadas (Tabelas 1 e 2).

Em relação às mulheres de 26 a 44 anos de idade, os principais fatores associados à infecção genital por HPV na análise bivariada foram a coitarca, número de parceiros sexuais durante a vida e no último ano, bem como história de sintomas genitais, sendo tais associações evidentes somente na amostra urbana (Tabela 1). As mulheres urbanas que tiveram sua iniciação sexual aos quinze anos ou menos e aquelas com relato de três ou mais parceiros sexuais durante a vida, tinham maior prevalência de infecção pelo HPV, no entanto tais associações não apresentaram significância estatística.

Por fim, as mulheres a partir dos 45 anos apresentaram especialmente os seguintes fatores associados à infecção genital por HPV na análise bivariada: número de parceiros sexuais durante a vida e novos no último ano, bem como uso de anticoncepcional oral; história de DST e tabagismo atual, e tais fatores se comportaram de forma diferenciada nas amostras urbana e rural (Tabelas 1 e 2). Mulheres urbanas que fizeram uso de anticoncepcionais orais ao longo da vida, fumantes declaradas, menor número de parceiros sexuais durante a vida e história de DST pregressa tiveram uma prevalência maior de infecção pelo HPV, sendo constatada associação significante somente em relação à história pregressa de DST ( $\mathrm{p}=0,0331$ ). Já na amostra rural os principais fatores associados ao HPV foram maior número de parceiros sexuais novos no último ano e tabagismo atual, e o hábito de fumar se associou significativamente à infecção por HPV com uma prevalência 6,9 ( $\mathrm{p}=0,0344)$ vezes maior em relação às não fumantes.

Os principais fatores que se mostraram associados à infecção pelo HPV com p-valor menor que 0,2 na análise bivariada, foram inseridas no modelo de regressão logística multivariado, sendo ajustada a variável "número de parceiros na vida" pela variável "uso de preservativos" na amostra urbana (Tabela 3). O ajuste se deveu ao fato de que $74,2 \%$ das mulheres urbanas com 45 anos ou mais, com menor número de parceiros sexuais durante a vida ( 1 a 2 parceiros), afirmaram nunca utilizar preservativo, enquanto entre as mulheres com 3 ou mais parceiros na vida o percentual caiu para $28 \%$, representando o "uso de preservativos" um fator de confundimento nessa análise.

Após o ajuste das variáveis, foi possível constatar a permanência de uma única associação significante: mulheres solteiras, separadas ou viúvas, de 13 a 25 anos, da amostra rural permaneceram independentemente associadas à infecção genital pelo HPV (Tabela 4).

\section{Discussão}

A saúde da mulher hoje no Brasil é um tema que abrange vários aspectos que tangem direta ou indiretamente as dimensões social, educacional e das políticas públicas de saúde. Estudos que envolvem todos esses pontos podem subsidiar estratégias mais coerentes e sinérgicas voltadas aos novos campos de atuação das políticas públicas, com uma abordagem ampliada dos processos de saúde-doença da população alvo. Neste contexto, vale ressaltar a importância da Pesquisa Nacional de Demografia em Saúde da Mulher e da Criança ${ }^{12}$, financiada pelo Ministério da Saúde e executada por uma equipe da área de População e Sociedade, e que tem traçado os 
Prevalência da infecção genital por HPV de acordo com fatores de risco para a aquisição e manutenção viral, nas diferentes faixas etárias da amostra urbana ( $N$ = 233). Belém, Pará, Brasil, 2008-2010. Análise bivariada.

\begin{tabular}{|c|c|c|c|c|c|c|c|c|c|c|c|c|}
\hline \multirow[t]{2}{*}{ Variáveis } & \multicolumn{4}{|c|}{$13-25$ anos $(n=42)$} & \multicolumn{4}{|c|}{$26-44 \operatorname{anos}(n=133)$} & \multicolumn{4}{|c|}{45 anos ou mais $(n=58)$} \\
\hline & $\mathrm{n}$ & HPV (\%) & RP & Valor de $p$ * & $\mathbf{n}$ & HPV (\%) & $\mathrm{RP}$ & Valor de $p$ * & $\mathbf{n}$ & HPV (\%) & RP & Valor de $p$ * \\
\hline \multicolumn{13}{|l|}{ Situação conjugal } \\
\hline Solteira/Separada/ & 20 & $3(15,0)$ & 0,7 & 0,4060 & 39 & $4(10,3)$ & 0,7 & 0,3417 & 18 & $3(16,7)$ & 1,1 & 0,5764 \\
\hline \multicolumn{13}{|l|}{ Viúva } \\
\hline Casada/União estável & 22 & $5(22,7)$ & & & 94 & $14(14,9)$ & & & 40 & $6(15,0)$ & & \\
\hline \multicolumn{13}{|l|}{ Escolaridade (anos) } \\
\hline$\leq 8$ & 5 & $1(20,0)$ & 1,1 & 0,6728 & 41 & $5(12,2)$ & 0,9 & 0,4998 & 35 & $6(17,1)$ & 1,3 & 0,4871 \\
\hline$>8$ & 37 & $7(18,9)$ & & & 92 & $13(14,1)$ & & & 23 & $3(13,0)$ & & \\
\hline \multicolumn{13}{|l|}{ Coitarca (anos) } \\
\hline$\leq 15$ & 16 & $2(12,5)$ & 0,5 & 0,3364 & 46 & $9(19,6)$ & 1,9 & 0,1392 & 13 & $2(15,4)$ & 1,0 & 0,6536 \\
\hline$>15$ & 26 & $6(23,1)$ & & & 87 & $9(10,3)$ & & & 45 & $7(15,6)$ & & \\
\hline \multicolumn{13}{|l|}{ Parceiros sexuais } \\
\hline \multicolumn{13}{|l|}{ durante a vida ** } \\
\hline 3 ou mais & 18 & $6(33,3)$ & 3,5 & 0,0749 & 98 & $17(17,3)$ & 6,0 & 0,0227 * & 27 & $2(7,4)$ & 0,3 & 0,1085 \\
\hline 1 ou 2 & 21 & $2(9,5)$ & & & 35 & $1(2,9)$ & & & 31 & $7(22,6)$ & & \\
\hline \multicolumn{13}{|l|}{ Parceiros sexuais novos } \\
\hline \multicolumn{13}{|l|}{ no último ano } \\
\hline 1 ou mais & 11 & $4(36,4)$ & 2,8 & 0,1074 & 14 & - & - & 0,1163 & 3 & - & - & 0,5970 \\
\hline Nenhum & 31 & $4(12,9)$ & & & 119 & $18(15,1)$ & & & 55 & $9(16,4)$ & & \\
\hline \multicolumn{13}{|l|}{ Uso de preservativos } \\
\hline Nunca/Às vezes & 28 & $4(14,3)$ & 0,5 & 0,2396 & 109 & $16(14,7)$ & 1,8 & 0,3269 & 56 & $9(16,1)$ & - & 0,7114 \\
\hline Regularmente & 14 & $4(28,6)$ & & & 24 & $2(8,3)$ & & & 2 & - & & \\
\hline \multirow{2}{*}{\multicolumn{13}{|c|}{$\begin{array}{l}\text { Anticoncepcional na } \\
\text { vida }\end{array}$}} \\
\hline & & & & & & & & & & & & \\
\hline $\operatorname{Sim}$ & 26 & $4(15,4)$ & 0,6 & 0,3514 & 92 & $11(12,0)$ & 0,7 & 0,4257 & 36 & $8(22,2)$ & 4,9 & 0,0714 \\
\hline Não & 16 & $4(25,0)$ & & & 41 & $7(17,1)$ & & & 22 & $1(4,5)$ & & \\
\hline \multicolumn{13}{|l|}{ História de DST } \\
\hline $\operatorname{Sim}$ & 11 & $1(9,1)$ & 0,4 & 0,3119 & 27 & $5(18,5)$ & 1,5 & 0,2860 & 7 & $3(42,9)$ & 3,6 & 0,0331 * \\
\hline Não & 31 & $7(22,6)$ & & & 106 & $13(12,3)$ & & & 51 & $6(11,8)$ & & \\
\hline \multicolumn{13}{|l|}{ Sintomas genitais } \\
\hline $\operatorname{Sim}$ & 38 & $8(21,1)$ & - & 0,4143 & 119 & $14(11,8)$ & 0,4 & 0,0983 & 48 & $7(14,6)$ & 0,7 & 0,4881 \\
\hline Não & 4 & - & & & 14 & $4(28,6)$ & & & 10 & $2(20,0)$ & & \\
\hline \multicolumn{13}{|l|}{ Tabagismo atual } \\
\hline $\operatorname{Sim}$ & 5 & - & - & 0,3271 & 11 & $1(9,1)$ & 0,7 & 0,5441 & 5 & $2(40,0)$ & 3,0 & 0,1676 \\
\hline Não & 37 & $8(21,6)$ & & & 122 & $17(13,9)$ & & & 53 & $7(13,2)$ & & \\
\hline
\end{tabular}

DST: doenças sexualmente transmissíveis; RP: razão de prevalência; (-): dado numérico igual a zero.

* Teste do qui-quadrado ou exato de Fisher (nível $\alpha=5 \%$ );

** Variável com alguns dados ignorados.

avanços na área de saúde da mulher e da criança, permitindo, inclusive, comparações com estudos internacionais.

Atualmente, são considerados aspectos importantes para o incremento da vulnerabilidade feminina à ocorrência de altos índices de morte por câncer de colo no Brasil aspectos socioculturais e político-econômicos, com destaque para a escolaridade, acesso aos serviços de prevenção e manejo do câncer cervical, hábitos de vida, bem como os diferentes grupos etários e sua região de residência. Os dois últimos fatores têm sido apontados como significativos determinantes sociais em saúde, uma vez que mulheres vivendo em áreas geográficas com pouco ou nenhum acesso aos serviços públicos de promoção, 
Prevalência da infecção genital por HPV de acordo com fatores de risco para a aquisição e manutenção viral, nas diferentes faixas etárias da amostra rural ( $N$ = 211). Tucuruí, Pará, Brasil, 2008-2010. Análise bivariada.

\begin{tabular}{|c|c|c|c|c|c|c|c|c|c|c|c|c|}
\hline \multirow[t]{2}{*}{ Variáveis } & \multicolumn{4}{|c|}{$13-25$ anos $(n=64)$} & \multicolumn{4}{|c|}{$26-44$ anos $(n=101)$} & \multicolumn{4}{|c|}{45 anos ou mais $(n=46)$} \\
\hline & n & HPV (\%) & RP & $\begin{array}{l}\text { Valor } \\
\text { de } p \text { * }\end{array}$ & $\mathbf{n}$ & HPV (\%) & RP & $\begin{array}{l}\text { Valor } \\
\text { de } p \text { * }\end{array}$ & $\mathbf{n}$ & HPV (\%) & $\mathrm{RP}$ & $\begin{array}{l}\text { Valor } \\
\text { de } p \text { * }\end{array}$ \\
\hline \multicolumn{13}{|l|}{ Situação conjugal } \\
\hline Solteira/Separada/Viúva & 14 & $6(42,9)$ & 4,3 & 0,0097 * & 12 & - & - & 0,1487 & 7 & $1(14,3)$ & 1,4 & 0,5799 \\
\hline Casada/União estável & 50 & $5(10,0)$ & & & 89 & $14(15,7)$ & & & 39 & $4(10,3)$ & & \\
\hline \multicolumn{13}{|l|}{ Escolaridade (anos) } \\
\hline$\leq 8$ & 46 & $8(17,4)$ & 1,0 & 0,6296 & 82 & $12(14,6)$ & 1,4 & 0,4842 & 35 & $5(14,3)$ & - & 0,2368 \\
\hline$>8$ & 18 & $3(16,7)$ & & & 19 & $2(10,5)$ & & & 11 & - & & \\
\hline \multicolumn{13}{|l|}{ Coitarca (anos) } \\
\hline$\leq 15$ & 46 & $8(17,4)$ & 1,0 & 0,6296 & 51 & $6(11,8)$ & 0,7 & 0,5379 & 19 & $2(10,5)$ & 0,9 & 0,6502 \\
\hline$>15$ & 18 & $3(16,7)$ & & & 50 & $8(16,0)$ & & & 26 & $3(11,5)$ & & \\
\hline \multicolumn{13}{|l|}{ Parceiros sexuais durante } \\
\hline \multicolumn{13}{|l|}{ a vida ** } \\
\hline 3 ou mais & 39 & $8(20,5)$ & 1,6 & 0,3246 & 45 & $6(13,3)$ & 0,9 & 0,8039 & 12 & $1(8, \prime)$ & 0,6 & 0,5687 \\
\hline 1 ou 2 & 24 & $3(12,5)$ & & & 53 & $8(15,1)$ & & & 31 & $4(12,9)$ & & \\
\hline \multicolumn{13}{|l|}{ Parceiros sexuais novos } \\
\hline \multicolumn{13}{|l|}{ no último ano } \\
\hline 1 ou mais & 10 & $3(30,0)$ & 2,0 & 0,2276 & 13 & - & - & 0,1253 & 2 & $1(50,0)$ & 5,5 & 0,2077 \\
\hline Nenhum & 54 & $8(14,8)$ & & & 88 & $14(15,9)$ & & & 44 & $4(9,1)$ & & \\
\hline \multicolumn{13}{|l|}{ Uso de preservativos } \\
\hline Nunca/Às vezes & 55 & $8(14,5)$ & 0,4 & 0,1772 & 95 & $14(14,7)$ & - & 0,3984 & 44 & $5(11,4)$ & - & 0,7922 \\
\hline Regularmente & 9 & $3(33,3)$ & & & 6 & - & & & 2 & - & & \\
\hline \multicolumn{13}{|l|}{ Anticoncepcional na vida } \\
\hline $\operatorname{Sim}$ & 41 & $6(14,6)$ & 0,7 & 0,3465 & 52 & $7(13,5)$ & 0,9 & 0,9046 & 16 & - & - & 0,1039 \\
\hline Não & 23 & $5(21,7)$ & & & 49 & $7(14,3)$ & & & 30 & $5(16,7)$ & & \\
\hline \multicolumn{13}{|l|}{ História de DST } \\
\hline $\operatorname{Sim}$ & 9 & - & - & 0,1609 & 18 & $1(5,6)$ & 0,4 & 0,2371 & 12 & $1(8,3)$ & 0,7 & 0,6089 \\
\hline Não & 55 & $11(20,0)$ & & & 83 & $13(15,7)$ & & & 34 & $4(11,8)$ & & \\
\hline \multicolumn{13}{|l|}{ Sintomas genitais } \\
\hline $\operatorname{Sim}$ & 58 & $10(17,2)$ & 1,0 & 0,6937 & 94 & $13(13,8)$ & 1,0 & 0,6602 & 41 & $4(9,8)$ & 0,5 & 0,4532 \\
\hline Não & 6 & $1(16,7)$ & & & 7 & $1(14,3)$ & & & 5 & $1(20,0)$ & & \\
\hline \multicolumn{13}{|l|}{ Tabagismo atual } \\
\hline $\operatorname{Sim}$ & 5 & $1(20,0)$ & 1,2 & 06236 & 27 & $4(14,8)$ & 1,1 & 0,5475 & 17 & $4(23,5)$ & 6,9 & 0,0344 * \\
\hline Não & 59 & $10(16,9)$ & & & 74 & $10(13,5)$ & & & 29 & $1(3,4)$ & & \\
\hline
\end{tabular}

DST: doenças sexualmente transmissíveis; RP: razão de prevalência; (-): dado numérico igual a zero.

* Teste do qui-quadrado ou exato de Fisher (nível $\alpha=5 \%$ );

** Variável com alguns dados ignorados.

prevenção e recuperação da saúde; associados a traços psicossociais característicos da mulher adolescente, adulta ou idosa, podem interferir de maneira interdependente no perfil de morbimortalidade por câncer cervical 13,14 .

Em nosso estudo investigamos a epidemiologia da infecção genital pelo HPV em relação aos fatores de risco sociodemográficos, comportamentais, sexuais e reprodutivos de duas popu- lações distintas da Amazônia Oriental Brasileira, composta de mulheres que vivem em aglomerado urbano e rural, assim como fatores clínicos relativos à colpocitologia (PCCU) e diagnóstico molecular da presença genital do DNA do HPV.

Tendo em conta as idades de todas as mulheres incluídas no estudo, houve um predomínio da faixa de 26 a 44 anos, seguida pela faixa de 13 a 25 anos e pela de 45 e mais, mas a distribuição 
Razão de chances de prevalência para os fatores independentemente associados à infecção genital pelo HPV, de acordo com o resultado final do modelo de regressão logística multivariado. Amostra urbana, Belém, Pará, Brasil, 2008-2010.

\begin{tabular}{|c|c|c|c|c|c|c|c|c|c|}
\hline \multirow[t]{2}{*}{ Variáveis } & \multicolumn{3}{|c|}{$13-25$ anos } & \multicolumn{3}{|c|}{$26-44$ anos } & \multicolumn{3}{|c|}{45 anos ou mais } \\
\hline & ORp & IC95\% & $\begin{array}{c}\text { Valor } \\
\text { de } p \text { * }\end{array}$ & ORp & IC95\% & $\begin{array}{c}\text { Valor } \\
\text { de } p \text { * }\end{array}$ & ORp & IC95\% & $\begin{array}{l}\text { Valor } \\
\text { de } p \text { * }\end{array}$ \\
\hline Coitarca & $\star \star *$ & $\star \star *$ & $\star \star$ & 1,9 & $0,66-5,45$ & 0,2373 & $\star \star$ & $\star \star$ & $\star \star$ \\
\hline 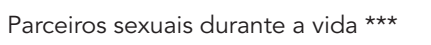 & 2,5 & $0,35-18,04$ & 0,3609 & 7,2 & $0,90-58,20$ & 0,0632 & 0,2 & $0,05-1,45$ & 0,1286 \\
\hline Parceiros sexuais novos no último ano & 3,2 & $0,48-21,88$ & 0,2284 & $\star \star$ & $\star \star$ & $\star \star$ & $\star \star$ & $\star \star$ & $\star \star$ \\
\hline Anticoncepcional na vida & ** & ** & ** & $\star \star$ & $\star \star$ & $\star \star$ & 7,6 & $0,74-77,69$ & 0,0874 \\
\hline História de DST & $\star \star *$ & $\star \star \star$ & $\star \star$ & $\star \star$ & $\star \star$ & $\star \star$ & 7,7 & $0,94-63,00$ & 0,0572 \\
\hline Sintomas genitais & $\star \star$ & $\star \star$ & $\star \star \star$ & 0,5 & $0,11-1,95$ & 0,2896 & $\star \star$ & $\star \star$ & $\star \star$ \\
\hline Tabagismo atual & $\star \star$ & $\star \star$ & $\star \star$ & $\star \star$ & $\star \star$ & $\star \star$ & 3,9 & $0,43-34,54$ & 0,2256 \\
\hline
\end{tabular}

DST: doenças sexualmente transmissíveis; IC95\%: intervalo de 95\% de confiança; ORp: razão de chances de prevalência.

* Modelo de regressão logística com variáveis selecionadas na análise bivariada (nível $\alpha=5 \%$ );

** Variáveis não incluídas no modelo de regressão logística;

*** Variável ajustada no modelo de regressão logística pela variável "uso de preservativos".

Razão de chances de prevalência para os fatores independentemente associados à infecção genital pelo HPV, de acordo com o resultado final do modelo de regressão logística multivariado. Amostra rural, Tucuruí, Pará, Brasil, 2008-2010.

\begin{tabular}{|c|c|c|c|c|c|c|c|c|c|}
\hline \multirow[t]{2}{*}{ Variáveis } & \multicolumn{3}{|c|}{$13-25$ anos } & \multicolumn{3}{|c|}{$26-44$ anos } & \multicolumn{3}{|c|}{45 anos ou mais } \\
\hline & ORp & IC95\% & $\begin{array}{l}\text { Valor } \\
\text { de p * }\end{array}$ & ORp & IC95\% & $\begin{array}{c}\text { Valor } \\
\text { de } p \text { * }\end{array}$ & ORp & IC95\% & $\begin{array}{l}\text { Valor } \\
\text { de } p \text { * }\end{array}$ \\
\hline Situação conjugal & 6,7 & $1,29-35,20$ & 0,0237 & $\star \star$ & $\star \star$ & $\star \star$ & ** & $\star \star$ & ** \\
\hline Parceiros sexuais novos no último ano & $\star \star$ & $\star \star$ & $\star \star$ & $\star \star$ & $\star \star$ & ** & 6,9 & $0,20-232,47$ & 0,2840 \\
\hline Uso de preservativos & 0,9 & $0,13-6,33$ & 0,9147 & $\star \star$ & $\star \star$ & $\star \star$ & $\star \star$ & $\star \star$ & $\star \star$ \\
\hline Tabagismo atual & $\star \star$ & $\star \star$ & $\star \star$ & $\star \star$ & $\star \star$ & ** & 10,7 & $0,93-124,78$ & 0,0576 \\
\hline
\end{tabular}

IC95\%: intervalo de 95\% de confiança; ORp: razão de chances de prevalência.

* Modelo de regressão logística com variáveis selecionadas na análise bivariada (nível $\alpha=5 \%$ );

** Variáveis não incluídas no modelo de regressão logística.

de mulheres nessas faixas de idade se comportou de maneira semelhante no aglomerado urbano e no rural. Em estudo realizado por Molano et al. 6 também foram recrutadas mulheres em uma larga faixa de idade, entre 13 a 85 anos, a fim de se estudar a história natural do HPV em uma coorte colombiana, ocorrendo predomínio da faixa compreendida entre 25 e 34 anos. Além disso, sabe-se que nos serviços públicos de saúde a busca pela realização de rastreamento para o câncer cervical é maior entre mulheres abaixo de 35 anos ${ }^{1}$.

A grande maioria era casada ou vivia com um companheiro, tanto na amostra urbana quan- to na rural, permitindo a dedução da existência de maior atividade sexual monogâmica e fixa, a exemplo das participantes dos estudos de Silva et al. 15 no Paraná, onde as casadas ou que viviam em união estável representavam o maior percentual em análises epidemiológicas de amostras de PCCU de rotina.

O DNA do HPV foi detectado em 14,6\% da amostra geral da Amazônia Oriental brasileira, estando dentro do perfil de prevalência encontrada em estudos realizados em diversas regiões. Em estudo de coorte realizado por Molano et al. 6 com diagnóstico por PCR, foi verificada uma prevalência de 14,9\% em colombianas de 13 a 85 
anos. No Brasil, Trottier et al. 16 apontaram uma frequência de 10,6\% de HPV em mulheres de 18 a 60 anos, enquanto Franco et al. 7 apontaram a prevalência inicial de HPV de $13,8 \%$ para mulheres na mesma faixa de idade e de $25 \%$ acumulada ao final do seguimento do seu estudo.

A considerar a realidade urbana versus rural, encontrar-se-á uma maior prevalência de HPV na amostra urbana em contraposição à rural. Porém, em estudos realizados por Soares et al. 8 em área rural do Nordeste brasileiro foi detectada positividade para o HPV de $26 \%$, embora não tenham sido empregados neste estudo técnicas moleculares de diagnóstico do HPV.

Para um melhor entendimento da ocorrência do HPV nas duas populações estudadas, as mulheres foram divididas em três faixas de idade, e a maior ocorrência de HPV se deu entre as mulheres de 13 a 25 anos para todos os grupos do estudo. Além disso, houve um segundo pico de prevalência entre as mulheres de 45 anos ou mais na amostra urbana, não ocorrendo o mesmo com a amostra rural. Tal fato também foi berificado por Franceschi et al. 17, em um grande estudo Transversal com 18.498 mulheres de 15 regiões do mundo, utilizando diagnóstico por PCR, um comportamento bimodal de prevalência do HPV em mulheres da América Latina, estando o primeiro pico concentrado entre mulheres de 15 a 25 anos e o segundo a partir dos 45 anos.

O primeiro pico de prevalência entre adolescentes e mulheres jovens pode ser explicado por ser este o grupo etário no qual se inicia a vida sexual, sendo característica a maior frequência de atividade sexual, rotatividade de parceiros e procura por parceiros novos, uso irregular de métodos contraceptivos de barreira e fragilidade da cérvice uterina no início da vida sexual, além dos traços psicossociais desse grupo etário, que normalmente não procura os serviços de saúde com a mesma regularidade que as mulheres mais velhas para fins preventivos.

O segundo pico entre mulheres de meia idade e idosas ocorre, segundo Trottier \& Franco 18 e Herrero et al. ${ }^{19}$, em razão de uma provável reativação de infecção latente pela perda gradual da imunidade tipo específica pós-menopausa, possível aquisição de novas infecções provenien- tes de novos parceiros sexuais ou simplesmente relacionada ao efeito de coorte de nascimento. O último consistiria numa diversidade de exposição ao HPV de acordo com os diferentes momentos históricos de nascimento da mulher, mas a moral e os costumes sexuais de cada época podem modular a exposição a diversos fatores de risco normalmente relacionados à aquisição e à persistência viral.

O único fator de risco explorado no estudo que se mostrou significativamente associado à infecção pelo HPV e permaneceu no modelo final de regressão logística foi "a situação conjugal de mulheres residentes na zona rural na faixa de 13 a 25 anos", pois se encontrou prevalência de infecção genital significativamente maior em mulheres solteiras, separadas ou viúvas.

As limitações do estudo se relacionaram sobretudo ao uso de formulários para a coleta de dados referentes aos fatores de risco para aquisição e manutenção do HPV, uma vez que as associações estatísticas foram realizadas exclusivamente com base nas informações relatadas pelas mulheres com possibilidade de ocultação da verdade e mascaramento de resposta. Além disso, o delineamento transversal não permitiu a utilização da temporalidade como critério de causa para o HPV, uma vez que fatores de risco e desfecho foram vistos em um mesmo momento e o viés da causalidade reversa não pôde ser eliminado.

Por fim, acredita-se que os resultados obtidos neste estudo podem subsidiar a reorganização de estratégias voltadas à saúde da mulher no tocante à prevenção e ao manejo específico da infecção por HPV tendo em vista as particularidades de cada grupo etário e seu local de trabalho e residência. O maior conhecimento, por parte da mulher, sobre as formas de aquisição, fatores de risco e frequência da infecção por HPV em grupos etários e populacionais distintos pode, provavelmente, contribuir para que ela tenha maior percepção em relação ao seu risco de desenvolver lesões pré-neoplásicas cervicais e, consequentemente, influenciar a sua adesão permanente às atividades de PCCU e/ou estimular modificações de comportamentos e estilos de vida considerados de risco para o HPV. 


\section{Resumo}

Foram investigados a prevalência e os fatores associados à infecção genital pelo HPV em mulheres de população urbana e rural de duas regiões da Amazônia Oriental brasileira. Foi um estudo transversal com 444 mulheres submetidas ao rastreamento para câncer cervical, sendo 233 urbanas e 211 rurais, de janeiro de 2008 a março de 2010. Coletaram-se amostras da cérvice uterina para a pesquisa de DNA do HPV pela PCR. Todas responderam a um formulário epidemiológico. Análise bivariada e por regressão logística foram empregadas na investigação dos fatores associados ao HPV. A prevalência geral de HPV foi de 14,6\%. Entre as populações, não houve diferença significativa, 15\% urbana e 14,2\% rural. O único fator de risco explorado no estudo significativamente associado ao HPV foi a situação conjugal de mulheres residentes na zona rural na faixa de 13 a 25 anos, com maior prevalência de infecção entre solteiras, separadas ou viúvas. Concluise que, apesar das prevalências entre as populações serem semelhantes, as estratégias preventivas a serem aplicadas seriam específicas para cada população.

Infecções por Papillomavirus; Colo do Útero; Mulheres

\section{Colaboradores}

D. S. Pinto, H. T. Fuzii e J. A. S. Quaresma participaram da concepção e projeto do artigo, delineamento do estudo, análise e interpretação dos dados, revisão crítica e redação do manuscrito.

\section{Agradecimentos}

À Secretaria de Vigilância em Saúde do Ministério da Saúde e, à UNESCO e à ELETROBRAS/ELETRONORTE pelo apoio financeiro.

\section{Referências}

1. Coordenação de Prevenção e Vigilância de Câncer, Instituto Nacional de Câncer. Prevenção do câncer do colo do útero: normas e recomendações do INCA. Rev Bras Cancerol 2003; 49:205.

2. Coordenação de Prevenção e Vigilância de Câncer, Instituto Nacional de Câncer. Estimativas 2010: incidência de câncer no Brasil. Rio de Janeiro: Instituto Nacional de Câncer; 2009.

3. Tulio S, Pereira LA, Neves FB, Pinto AP. Relação entre a carga viral de HPV oncogênico determinada pelo método de captura híbrida e o diagnóstico citológico de lesões de alto grau. J Bras Patol Med Lab 2007; 43:31-5.

4. De Sanjosé S, Diaz M, Castellsagué X, Clifford G, Bruni I, Muñoz N, et al. Worldwide prevalence and genotype distribution of cervical human papillomavirus DNA in women with normal cytology: a meta-analysis. Lancet Infect Dis 2007; 7:453-9.

5. Bosh FX, Burchell AN, Schiffman M, Giuliano AR, De Sanjosé S, Bruni L, et al. Epidemiology and natural history of human papillomavirus infections and type-specific implications in cervical neoplasia. Vaccine 2008; 26 Suppl 10:1-16.

6. Molano M, Posso H, Méndez F, Murillo R, Van Den Brulle A, Ronderos M, et al. Historia natural de la infección por el virus del papiloma humano en una cohorte de Bogotá, D.C., Colombia. Rev Colomb Cancerol 2005; 9:209-26. 
7. Franco EL, Villa LL, Sobrinho JP, Prado JM, Rousseau MC, Désy M, et al. Epidemiology of acquisition and clearance of cervical human papillomavirus infection in women from a high-risk area for cervical cancer. J Infect Dis 1999; 180:1415-23.

8. Soares VLS, Mesquita AMTS, Cavalcante FGT, Silva ZP, Hora V, Diedrich T, et al. Sexually transmitted infections in a female population in rural northeast Brazil: prevalence, morbidity and risk factors. Trop Med Int Health 2003; 8:595-603.

9. Departamento de Atenção Básica, Secretaria de Atenção à Saúde, Ministério da Saúde. Cadernos de atenção básica: controle dos cânceres do colo do útero e da mama. Brasília: Ministério da Saúde; 2006.

10. Solomon D, Davey D, Kurman R, Moriarty A, O'Connor D, Prey M, et al. The 2001 Bethesda System: terminology of reporting results of cervical cytology. JAMA 2002; 287:2114-9.

11. Bernard HU, Chan SY, Manos MM, Ong CK, Villa LL, Delius H. Identification and assessment of known and novel human papillomaviruses by polymerase chain reaction amplification, restriction fragment length polymorphisms, nucleotide sequence, and phylogenetic algorithms. J Infect Dis 1994; 170:1077-85.

12. Ministério da Saúde/Centro Brasileiro de Análise e Planejamento. Pesquisa Nacional de Demografia e Saúde da Criança e da Mulher - PNDS 2006: dimensões do processo reprodutivo e da saúde da criança. Brasília: Ministério da Saúde; 2009.
13. Departamento de Ações Programáticas Estratégicas, Secretaria de Atenção à Saúde, Ministério da Saúde. Política nacional de atenção integral à saúde da mulher: plano de ação 2004-2007. Brasília: Ministério da Saúde; 2004.

14. Departamento de Análise de Situação em Saúde, Secretaria de Vigilância em Saúde, Ministério da Saúde. Saúde Brasil 2006: uma análise da situação de saúde no Brasil. Brasília: Ministério da Saúde; 2006.

15. Silva TT, Guimarães ML, Barbosa MIC, Pinheiro MFG, Maia AF. Identificação de tipos de papilomavirus e de outros fatores de risco para neoplasia intraepitelial cervical. Rev Bras Ginecol Obstet 2006; 28:385-91.

17. Trottier H, Salaheddin M, Prado JCM, Sobrinho JS, Costa MC, Rohan TE, et al. Type-specific duration of human papillomavirus infection: implications for human papillomavirus screening and vaccination. J Infect Dis 2008; 197:1436-47.

18. Franceschi S, Herrero R, Clifford GM, Snijders PJF Arslan A, Anh PTH, et al. Variations in the age-specific curves of human papilomavirus prevalence in women worldwide. Int J Cancer 2006; 119:2677-84.

19. Trottier H, Franco EL. The epidemiology of genital human papillomavirus infection. Vaccine 2006; 24 Suppl 1:S4-15.

20. Herrero R, Castle PE, Schiffman M, Herrero R, Castle PE, Schiffman M, et al. Epidemiologic profile of type-specific human papillomavirus infection and cervical neoplasia in Guanacaste, Costa Rica. J Infect Dis 2005; 191:1796-807.

Recebido em 21/Abr/2010

Versão final reapresentada em 25/Jan/2011 Aprovado em 01/Fev/2011 